Supporting Information

\title{
A SERS Nanoprobe for Intracellular Monitoring of Viral Mutations
}

Kholud Dardir," Hao Wang, ${ }^{\#}$ Brigitte E. Martin, Maria Atzampou, Christopher B. Brooke and Laura Fabris*

K. Dardir

Department of Chemistry and Chemical Biology, Rutgers University, 610 Taylor Road, Piscataway, NJ 08854, USA

M. Atzampou

Department of Biomedical Engineering, Rutgers University, 599 Taylor Road, Piscataway, NJ 08854, USA

Dr. BE Martin, Prof. CB Brooke

Department of Microbiology, University of Illinois at Urbana Champaign, Urbana, IL, USA Carl R. Woese Institute for Genomic Biology, University of Illinois at Urbana Champaign, Urbana, IL, USA

Dr. H. Wang, Prof. L. Fabris

Department of Materials Science and Engineering, Rutgers University, 607 Taylor Road, Piscataway, NJ 08854, USA

E-mail: Ifabris@soe.rutgers.edu

"Equal contribution

Keywords: nanostars, SERS, intracellular viral detection, viral mutation, influenza A 


\section{Table of Contents}

\section{Supporting Section 1. Experimental Details.}
A. Materials and cells
B. Gold nanostar synthesis and characterization
C. Recognition moiety and target oligonucleotides
D. Fabrication of SERS active nanostar probes
E. Single particle SERS anlysis via SERS active gold nanostar substrates and characterization
F. Raman measurements
G. Cell culture and single cell analysis

\section{Figures.}

- Figure S1 - Schematic diagram of gold nanoparticle synthesis

- Figure S2 - TEM and UV-Vis of silica etched nanostar particles

- Figure S3 - DLS measurements of DNA functionalized AuNSs

- Figure S4 - Particle stability at tissue culture incubation temperature

- Figure S5 - Particle stability over time

- Figure S6 - SANSP Substrate characterization

- Figure S7 - Dark-field image and SERS of SANSPs single particle analysis

- Figure S8 - Raman maps of sub-monolayer substrates after different treatment

- Figure S9 - Raman heatmaps measured after hybridization of SANSPs with RNA targets with different numbers of mutations

- Figure S10 - Histogram distributions of the peak intensities and ANOVA of group-means

- Figure S11 - Intracellular detection of viral RNA segments in transfected cells

- Figure S12 - Intracellular detection of viral RNA segments in transfected cells (controls)

\section{Tables.}

- Table S1 - Oligonucleotides

- Table S2 - The thermodynamic properties of the designed beacon structures

- Table S3 - Statistics for one-way ANOVA 


\section{Supporting Section 1. Experimental Details}

\section{A. Materials and Cells}

Tetrachloroauric(III) acid trihydrate, citric acid trisodium salt dihydrate, hydrochloric acid, ascorbic acid, hydrogen peroxide, and sodium borohydride were purchased from Fisher Scientific. Silver nitrate, tetraethyl orthosilicate, sulfuric acid, (3-aminopropyl)triethoxysilane (APTES), Tris(2-carboxyethyl)phosphine hydrochloride (TCEP), and ammonium hydroxide were purchased from Sigma-Aldrich. Cetyltrimethyl ammonium bromide (CTAB) was purchased from GFS Chemicals. The oligonucleotides were customized and purchased from IDT DNA. Polyethylene glycol (PEG) was purchased from Pegworks. HeLa cells, Eagle's minimum essential medium (EMEM) were purchased for ATCC. Phosphate-Buffered Saline (PBS), Fetal Bovine Serum (FBS), Penstrep, Vybrant MTT cell proliferation assay kit, 96-well plates, 8-well chambered coverglass, and DECP-treated water were purchased from Thermo Fisher. Cell Lysis Buffer was purchased from Cell Signaling Technology. TEM grids were purchased from Ted Pella. JetPRIME transfection reagent was from Polyplus-transfection. IAV HA plasmids (pDZ-HA) and PB1/PB2 plasmids were kindly provided by the Chris Brooke group at UIUC.

\section{B. Gold Nanostar Synthesis and Characterization}

Surfactant free gold nanostars were synthesized via a seed mediated method described by Yuan et al. ${ }^{1}$ Citrate capped gold nanospheres were synthesized according to a modified synthesis described by Turkevich. ${ }^{2}$ Gold nanospheres were prepared by adding $8 \mathrm{~mL}$ of $0.025 \mathrm{M} \mathrm{HAuCl}_{4}$ salt to $477 \mathrm{~mL}$ of Milli-Q water and heated up to a boil under stirring. $15 \mathrm{~mL}$ of $1 \%$ citric acid trisodium salt were added to the mixture and left to boil for 5 minutes, after which the solution turned a deep red, and left to cool to room temperature. The product was purified via centrifugation at $6000 \mathrm{~g}$ for 30 to 45 minutes. The nanospheres settled at the bottom in a pellet, which was collected and characterized via Thermo Scientific Nanodrop 2000 UV-Vis spectrophotometer and a Philips CM12 transmission electron microscope (TEM).

Using the synthesized nanospheres, gold nanostars were synthesized by adding $2 \mathrm{~mL}$ of 0.025 $\mathrm{M} \mathrm{HAuCl}_{4}$ salt solution, $200 \mu \mathrm{L}$ of $1 \mathrm{~N} \mathrm{HCl}, 48 \mathrm{~mL}$ of Milli-Q water, and $125 \mu \mathrm{L}$ of $12 \mathrm{~nm}$ citrate capped spheres with an absorbance value of 2.81 at a $1 \mathrm{~mm}$ path length under gentle stirring. 2 $\mathrm{mL}$ of $3 \mathrm{mM} \mathrm{AgNO}_{3}$ and $1 \mathrm{~mL}$ of $100 \mathrm{mM}$ ascorbic acid were added simultaneously to the mixture, that was allowed to stir for 7 minutes and then turned a deep blue color. The resulting product was purified via centrifugation at $3000 \mathrm{~g}$ for 15 minutes and characterized via a Thermo Scientific Nanodrop 2000 UV-Vis spectrophotometer, a Philips CM12 transmission electron microscope (TEM), and a Malvern Zetasizer Nano-S for dynamic light scattering (DLS) and zeta potential.

Silica coated gold nanostars were synthesized via a modified Stöber method following a modified version of the protocol from Atta et al. ${ }^{3}$ The synthesized nanostars were mixed with $10 \mathrm{~mL}$ of 0.2 $\mathrm{M} \mathrm{CTAB}$ under gentle stirring and purified via centrifugation at $6500 \mathrm{~g}$ for 20 minutes. $50 \mu \mathrm{L}$ of tetraethylorthosilicate (TEOS) were added to $40 \mathrm{~mL}$ of $0.8 \mathrm{nM} \mathrm{CTAB-capped} \mathrm{nanostars} \mathrm{and}$ stirred gently for an hour. The $\mathrm{pH}$ of the mixture was then adjusted to 8.6 by $\mathrm{NH}_{4} \mathrm{OH}$ addition 
under gentle stirring for 24 hours. The resulting product was purified by centrifugation at $6500 \mathrm{~g}$ for 30-45 minutes.

The silica coated gold nanostars were then etched by adding $300 \mathrm{mg}$ of $\mathrm{NaBH}_{4}$ to $10 \mathrm{~mL}$ of 0.4 nM silica-coated gold nanostars under gentle stirring for 30 hours. The 30 hours of etching produced a silica shell covering the core of the stars and leaving the tips of the stars exposed.

Figure S1 illustrates a schematic diagram of the synthesis. The particles were characterized via Thermo Scientific Nanodrop 2000 UV-Vis spectrophotometer and a Philips CM12 transmission electron microscope (TEM) (Figure S2).

\section{Beacon Design and Target Oligonucleotides}

The recognition moieties were oligonucleotides with target specificity. The DNA beacon was determined from one of the influenza A virus (IAV) H1N1 genomic viral RNA sequences (vRNA), Hemagglutinin (HA). The sequence was chosen from the conserved region, namely 5'-TCA TTT TTG TTG CTT TTG TTT-3'. ${ }^{4}$ The beacon's design allows for targeting specificity to distinguish segment 4 from the other seven segments. To create the SERS active beacon and the hairpin structure, the 21-base pair sequence was flanked on each end with a short complementary sequence, CGTGCG and CGCACG. It was then tagged with a Cy3 dye at the 3' end to provide both a fluorescent and Raman response depending on its hybridization, and a thiol group to conjugate it to the gold surface of the silica coated nanostars. ${ }^{5}$ The beacon length and composition were determined for optimal folding to form a hairpin structure using the binding affinity calculated by an ad hoc tool freely available on the IDT website, the company we use to acquire the oligoucleotides. The final beacon sequence was: 5'-Thiol-MC6-CGTGCG TCA TTT

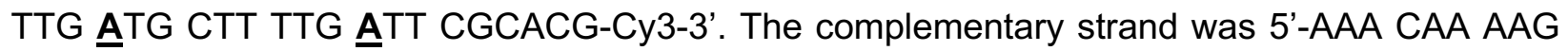
CAA CAA AAA TGA-3', target sequence was 5'-TCA TTT TTG TTG CTT TTG TTT-3' and the random/control sequence was 5'- TTT TAT CCT TCA TCT CTT GTA -3'.

For mutation detection, the target with 0 modifications, 5'-TCA TTT TTG TTG CTT TTG TTT-3', was compared to the target with 2, 4, 6, and 8 mismatches 5'-TCA TTT TTG TTG CTT TTG TTT3', 5'- TCA TGT TTG TTG CGT TTG TTT-3', 5'- TAA TTT TCG TTG CGT TTG TCT-3', 5'- TAA TTA TCG TTA CGT TTG TCT - 3', and 5'-TAA TTA TCG ATA CGT TAG TCT-3', with the modified base pairs in bold (Table S1).

\section{Fabrication of SERS Active Nanostar Probes (SANSPs)}

Silica coated nanostars were first conjugated with thiolated PEG (HS-PEG-NH $\mathrm{N}_{2}, 1000 \mathrm{MW}$ ), for added stability, ${ }^{6}$ and then with oligonucleotides. The thiolated PEG was added to $3 \mathrm{nM}$ of silica coated nanostars in a final concentration of $1.25 \mathrm{mM}$ under mild shaking for 30 minutes and then centrifuged at $3000 \mathrm{~g}$ for $10 \mathrm{~min} 3$ times. The particles were re-suspended in $\mathrm{DI}$ water ${ }^{7}$ and, then, the thiolated beacon DNA was added at a final concentration of $500 \mathrm{nM}$. The sample was incubated under gentle stirring for 30 minutes and, then, purified by centrifugation at $3500 \mathrm{~g}$ for 5 minutes 3 times. The preparation of the thiolated beacon DNA required mixing DNA beacon $(100 \mu \mathrm{M}), \mathrm{PBS}(\mathrm{pH} 7.4)$ and TCEP $(50 \mathrm{mM})$ in a 2:6:1 ratio. Next, the complementary strand was 
added at a final concentration of $500 \mathrm{nM}$, incubated under gentle stirring for 30 minutes and, then, purified by centrifugation at $3500 \mathrm{~g}$ for 5 minutes 3 times. Consequently, the target, random oligonucleotides were added with the same concentration as the complementary strand (500nM), incubated under gentle stirring for 30 minutes and, then, purified by centrifugation at $3500 \mathrm{~g}$ for 5 minutes 3 times. The DNA beacon and the RNA oligonucleotides were initially dissolved in DECPtreated water.

The SANSP's ON-OFF sequence was confirmed via SERS analysis with a Renishaw InVia Raman microscope with $633 \mathrm{~nm}$ HeNe laser excitation, at $0.101 \mathrm{~mW}$ laser power (Figure S3). To validate the use of silica coated nanostars over surfactant free nanostars the recovery signal of the beacon after target exposure was compared via SERS (Figure S4). To confirm temperature stability at tissue culture incubation, $37^{\circ} \mathrm{C}$, the SANSPs were prepared at $37^{\circ} \mathrm{C}$ and tested against the target RNA at $37^{\circ} \mathrm{C}$ using a Fisher Scientific Microtube Thermal Mixer (Figure S5). To test for the SANSPs stability over time, the silica coated nanostars functionalized with the unhybridized beacon were shielded from light and left at room temperature for 1 month. Additionally, the SANSPs were shielded from light and also left at room temperature for 1 month (Figure S6).

\section{E. Single Particle SERS Analysis via SERS Active Gold Nanostar Substrates and Characterization}

Glass slides or Si wafers were first cut into appropriate sizes $(8 \times 25 \mathrm{~mm})$ and rinsed with ultrapure water and ethanol for three times, respectively. After drying, the glass slides were further cleaned by piranha solution for 1 hour (3:1 mixture of concentrated $\mathrm{H}_{2} \mathrm{SO}_{4}: \mathrm{H}_{2} \mathrm{O}_{2}(30 \%)$ (Handle with caution. Extremely corrosive!) in a dish container (Pyrex). Then the clean substrates were again rinsed with copious amounts of water and ethanol for three times, respectively. The cleaned slides were further immersed in the $10 \%$ (V/V) APTES $^{8}$ ethanolic solution for 4 hours. Then the substrates were sequentially washed with ethanol under sonication for 3 times. Finally, the substrate slides were dried before further use. Gold nanostar colloidal solution was diluted $5 x$ and 10x for preparation of sub-monolayer nanoparticle coverage on APTES functionalized slides. In general, the slides were immersed in the colloidal solution for $30 \mathrm{~min}$, rinsed with Milli-Q water, and followed by a desilanization step (incubating the AuNS substrates in $1 \mathrm{mM} \mathrm{NaOH}$ for 3 hours) to remove the excess APTES on the substrate. Then the AuNS substrates were rinsed again with water and ethanol for three times, respectively. The sub-monolayer coverage of AuNS on the substrates was later confirmed by dark-field microscopy and SEM imaging. SERS measurements were conducted after the AuNS substrate were subject to the following treatment: P1) incubation for 3 hours with the Cy3 labelled molecular beacon DNA oligos (2-mismatch hp, $10 \mu \mathrm{L}, 100 \mu \mathrm{M}$ ) pre-treated by TCEP $(5 \mu \mathrm{L}, 100 \mathrm{mM})$ in PBS $(500 \mu \mathrm{L})$; P2) after P1, washing and drying, further incubate the substrate with complementary DNA oligos $(15 \mu \mathrm{L}, 100 \mu \mathrm{M})$ in PBS $(500 \mu \mathrm{L})$ for 3 hours; P3) after P2, washing and drying, further immerse the substrate with target DNA oligos (10 $\mu \mathrm{L}, 100 \mu \mathrm{M})$ in PBS $(500 \mu \mathrm{L})$ for 3 hours.

Single particle SERS measurements were performed on a Renishaw InVia system $(\lambda=633 \mathrm{~nm}$, $\mathrm{HeNe}$ laser, Melles Griot). The laser power was set at $0.75 \mathrm{~mW}$ to minimize possible 
photodamage of the sample. In typical Raman mapping of single gold nanostars, an area of interest $(\sim 20 \times 20 \mu \mathrm{m})$ with sub-monolayer coverage of AuNS was selected by the bright-field view and Raman signals were obtained for each pixels $(16 \times 16)$ with $3 \mathrm{~s}$ acquisition time. 50x objective (NA=0.75, Leica) and 100x objective (NA=0.85, Leica) were used for image visualization, excitation of the sample, and collection of Raman signals. Dark-field images were obtained from a Horiba Xplora system equipped with a dark-field objective (50x, NA=0.5). Part of the Raman mapping was conducted on the same Horiba Xplora system equipped with a HeNe laser with the laser power of $\sim 0.5 \mathrm{~mW}$ (after objective) and an acquisition time of $5 \mathrm{~s}$ per pixel.

\section{F. Cell Culture and Single Cell Analysis}

HeLa cells were cultured in Eagle's minimum essential medium that was supplemented with 5\% Penstrep and $10 \%$ Fetal Bovine Serum. The cells were grown at $37^{\circ} \mathrm{C}$ at $5 \% \mathrm{CO}_{2}$. Upon reaching $70-80 \%$ confluency, the HeLa cells were washed with $1 \mathrm{X}$ phosphate buffer saline (PBS), trypsinized, and re-suspended in fresh EMEM.

For the MTT assay, HeLa cells were counted and seeded in a 96-well tissue culture plate and incubated for 24 hours at $37^{\circ} \mathrm{C}$ at $5 \% \mathrm{CO}_{2}$ to allow proper attachment. The media was then replaced and $0 \mathrm{pM}(0 \mu \mathrm{g} / \mathrm{mL}$ or $0 \mathrm{NS} / \mathrm{mL}), 3.4 \mathrm{pM}\left(50 \mu \mathrm{g} / \mathrm{mL}\right.$ or $\left.20.5 \times 10^{11} \mathrm{NS} / \mathrm{mL}\right), 5.2 \mathrm{pM}(75$ $\mu \mathrm{g} / \mathrm{mL}$ or $\left.31.3 \times 10^{11} \mathrm{NS} / \mathrm{mL}\right), 6.9 \mathrm{pM}\left(100 \mu \mathrm{g} / \mathrm{mL}\right.$ or $\left.41.5 \times 10^{11} \mathrm{NS} / \mathrm{mL}\right), 8.6 \mathrm{pM}(125 \mu \mathrm{g} / \mathrm{mL}$ or $\left.51.8 \times 10^{11} \mathrm{NS} / \mathrm{mL}\right), 10.3 \mathrm{pM}\left(150 \mu \mathrm{g} / \mathrm{mL}\right.$ or $\left.62.0 \times 10^{11} \mathrm{NS} / \mathrm{mL}\right)$ of SANSPs were added and incubated for 24 hours. After 24 hours of incubation, the cell viability was measured from each concetration using a Vybrant MTT cell proliferation assay kit. Following the manufacturer's protocol, the media in each well was replaced with $100 \mu \mathrm{L}$ of fresh media with $10 \mu \mathrm{L}$ of $12 \mathrm{mM} \mathrm{3-}$ (4,5-dimethylthiazol-2-yl)-2,5-diphenyltertazolium bromide (MTT) and incubated at $37^{\circ} \mathrm{C}$ and $5 \%$ $\mathrm{CO}_{2}$ for 4 hours. $85 \mu \mathrm{L}$ of media were removed and $75 \mu \mathrm{L}$ of DMSO were added to each well. The concentration of live cells was determined by measuring the density at $540 \mathrm{~nm}$ of the formazan dye crystals produced as a result of metabolic activity of live cells.

The fluorescent tracking of SANSPs was carried out via FITC-labeled PEG (5000 MW). The thiolated FITC-labeled PEG was added to $3 \mathrm{nM}$ of nanostars in a final concentration of $1.25 \mathrm{mM}$ under mild shaking for 30 minutes and then the sample was centrifuged at $3000 \mathrm{~g}$ for $10 \mathrm{~min} 3$ times. The particles were re-suspended and incubated with HeLa cells. Upon cellular uptake, the HeLa cells were fixed and analyzed. Fluorescent images were acquired using a Nikon Eclipse TE2000-S microscope.

For viral RNA detection in cell lysate, HeLa cell were seeded in a $10 \mathrm{~cm}$ dish at a seeding density of $2.0 \times 10^{6}$ in $5 \%$ Penstrep and 10\% Fetal Bovine Serum supplemented EMEM. The cells were allowed to grow and attach for 24 hours at $37^{\circ} \mathrm{C}$ and $5 \% \mathrm{CO}_{2}$. The media was removed and the cells were washed with 1X PBS. Cell Lysis Buffer was used following the manufacturer's protocol. $400 \mu \mathrm{L}$ of $1 \mathrm{X}$ lysis buffer was added to the dish and incubated on ice for 5 minutes. The cells were then scraped and transferred to a $2 \mathrm{~mL}$ centrifuge tube. The cells were sonicated and centrifuged at $14,000 \mathrm{~g}$. The supernatant was then extracted for use. A fraction of extracted cell lysate, equivalent to 25,000 cells (amount seeded in an 8 -well chambered coverglass), was spiked with 
target RNA, 5'-TCA TTT TTG TTG CTT TTG TTT-3'. The SANSPs were introduced to the cell lysate and allowed to interact prior to SERS analysis with a $633 \mathrm{~nm}$ HeNe laser excitation, at $0.101 \mathrm{~mW}$ laser power.

For viral RNA detection on single cells, HeLa cells were seeded in an 8-well chambered coverglass at a seeding density of 25,000 cell / well in the supplemented EMEM, where they were allowed to grow and attach for 24 hours at $37^{\circ} \mathrm{C}$ and $5 \% \mathrm{CO}_{2}$. The cells were transfected with IAV H1N1 HA plasmid to express the HA segment. Separately, they were either left untreated, transfected with PB1 plasmid, and transfected with PB2 plasmid, as three controls to demonstrate SANSP selectivity. JetPRIME transfection reagent was used following the manufacturer's protocol. The plasmids were each diluted in $25 \mu \mathrm{L}$ JetPRIME buffer then vortexed to mix. JetPRIME reagent was then added to the mixture and mixed. $0.5 \mu \mathrm{L}$ of the mixture were added to each appropriate well and incubated for 24 hours. The media was removed, the cells were washed with 1X PBS, and fresh media was added. $50 \mu \mathrm{g} / \mathrm{mL}\left(3.4 \mathrm{pM}\right.$ or $\left.20.5 \times 10^{11} \mathrm{NS} / \mathrm{mL}\right)$ of SANSPs were added and incubated for 4 hours. After the 4-hour incubation, the media was removed and the cells were washed with $1 \mathrm{X}$ PBS. To fix the cells, $4 \%$ formaldehyde in $1 \mathrm{X}$ PBS was added to cover the surface of the cells and left to incubate for 10 minutes at room temperature. The solution was removed and the cells were washed with 1X PBS. The cells were allowed to dry and analyzed via SERS.

\section{G. Cell Culture and RT-qPCR Analysis}

For transfection, $500 \mathrm{ng}$ of plasmid (PB2, PB1, or HA) or mock without plasmid was mixed with $200 \mu \mathrm{L}$ jetPRIME buffer (Polyplus-transfection; Illkirch, France) and $1 \mu \mathrm{L}$ jetPrime reagent and incubated at room temperature for 10 minutes. The transfection mixture was added dropwise to Hela cells at $60 \%$ confluency in 6 -well cell culture plates and incubated at $37^{\circ} \mathrm{C}, 5 \% \mathrm{CO} 2$. At 24 hours post transfection, supernatant was removed, cells were washed thoroughly, dissociated from the plate, and cellular mRNA was extracted with RNeasy Mini kit (QIAGEN Hilden, Germany), according to manufacturer's instructions with DNase I treatment. For cDNA synthesis, $5 \mu \mathrm{L}$ vNA, $0.5 \mu \mathrm{L} 10 \mathrm{mM}$ dNTP mix (Sigma-Aldrich), and $1.0 \mu \mathrm{L}$ Uni12 (Hoffman 2001) (AGCAAAAGCAGG) were incubated at $65^{\circ} \mathrm{C}$ for 5 minutes then transferred to ice for 2 minutes. $1 \mu \mathrm{L}$ SUPERase In

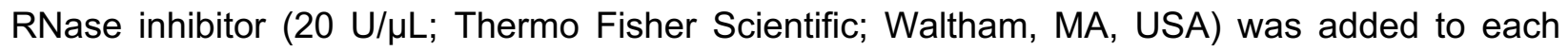
mixture and incubated on ice again for 2 minutes. $6.5 \mu \mathrm{L} \mathrm{dH} 2 \mathrm{O}, 4 \mu \mathrm{L} 5 \mathrm{X}$ First-Strand Buffer, $1 \mu \mathrm{L}$

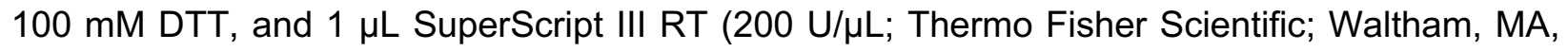
USA) were added to each reaction and incubated at $55^{\circ} \mathrm{C}$ for 60 minutes and heat inactivated at $70^{\circ} \mathrm{C}$ for 15 minutes.

Copy numbers were estimated by RT-qPCR of PB2, PB1, and HA gene segments. In triplicate for each sample, $10 \mu \mathrm{L}$ Power SYBR Green PCR master mix (Thermo Fisher Scientific; Waltham, MA, USA), $0.4 \mu \mathrm{L} \quad 10 \mu \mathrm{M}$ forward and reverse primers (PB2-Forward: ATCTAATGTCGCAGTCCCGC, PB2-Reverse: TTCTGAGTGCGGGGTTCTTC; PB1-Forward: GTCTAGGGCCCGGATTGATG, PB1-Reverse: GCCGTCTGAGTTCTTCAATGG; HA-Forward: GGCCACAGGATTGAGGAATA, HA-Reverse: TGGCATTCTGTGTGCTCTTC), $7.2 \mu \mathrm{L}$ dH2O, and $2 \mu \mathrm{L}$ cDNA were added to $0.2 \mathrm{~mL}$ MicroAmp Optical 96-well reaction plate (Thermo Fisher Scientific; Waltham, MA, USA). RT-qPCR was performed on the QuantStudio 3 (Thermo Fisher 
Scientific; Waltham, MA, USA) platform and the cycling conditions were as follows: $95^{\circ} \mathrm{C}$ for 10 minutes, 40 cycles of $95^{\circ} \mathrm{C}$ for 15 seconds and $60^{\circ} \mathrm{C}$ for 60 seconds. The standard curves established with pDZ-CA07 PB2 (R2 = 0.9987), pDZ-CA07 PB1 (R2 = 0.9986), and pDZ-CA07 HA plasmids $(R 2=0.9987)$ were used to estimate gene segment copy numbers for each primer pair set.

Figures.

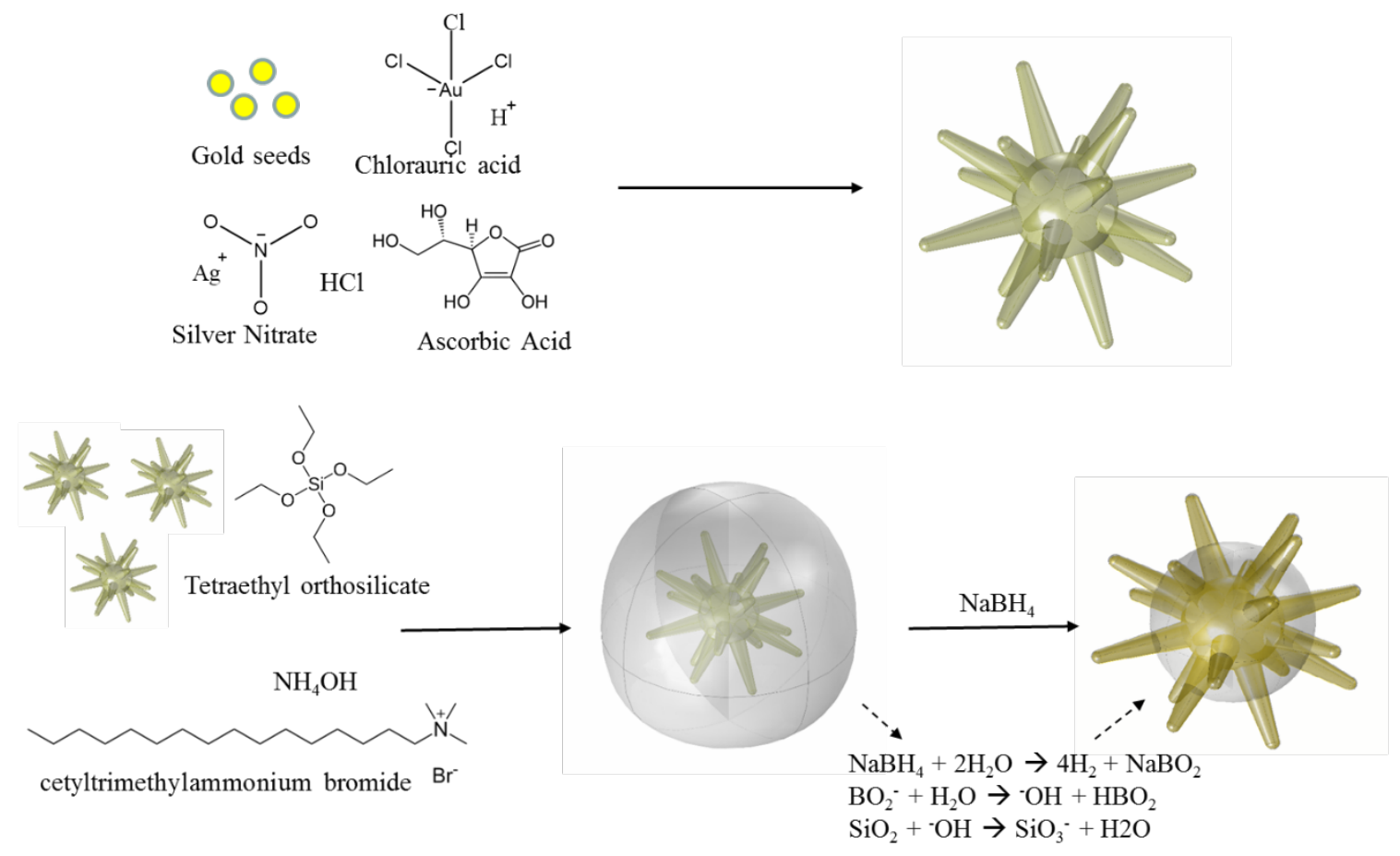

Figure S1. Step by step synthesis of the silica coated gold nanostars. ${ }^{9}$ 


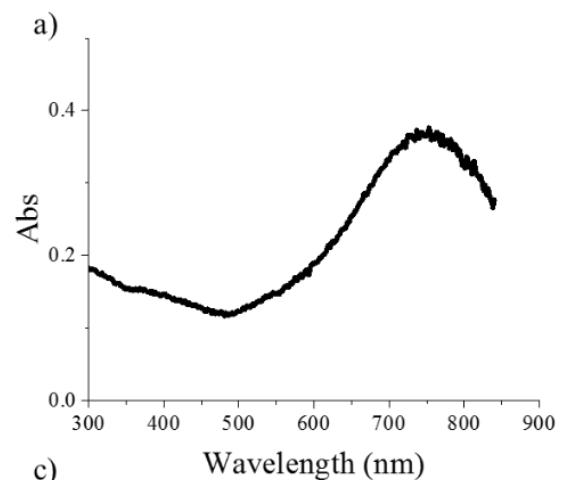

b)

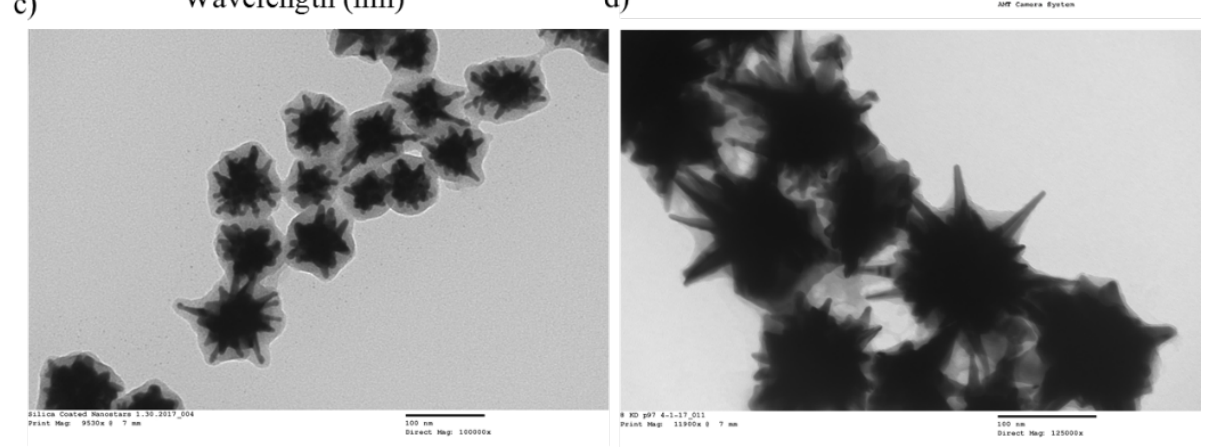

Figure S2. a) UV-Vis spectrum of the surfactant free gold nanostars. TEM micrographs of b) surfactant free gold nanostars, c) gold nanostars coated in a thick layer of silica prior to etching the silica coat with $\mathrm{NaBH}_{4}$, and d) gold nanostars with a thinner layer of slica exposing the gold surface on the tips of the spikes while coating the core of the nanostars. 

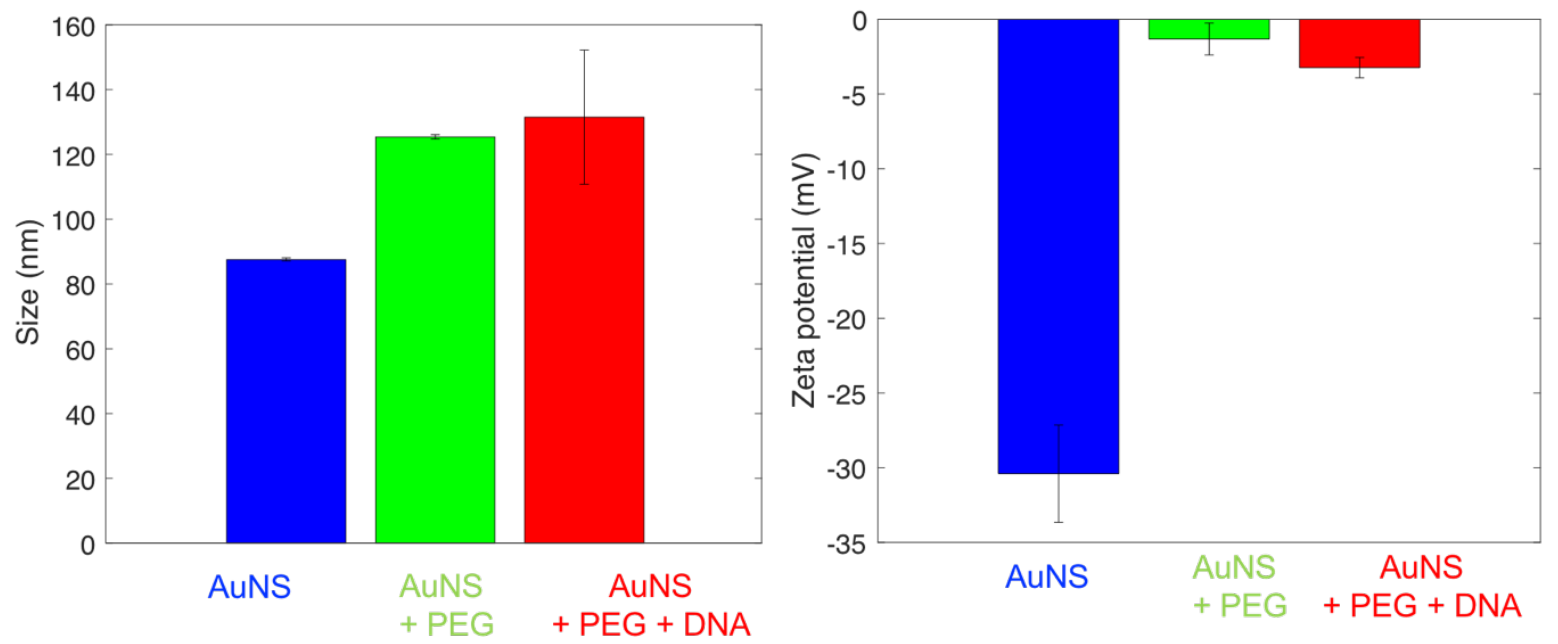

Figure S3. DLS size a) and zeta-potential b) measurement of the nanostar functionalization with PEG and DNA oligonucleotides. 

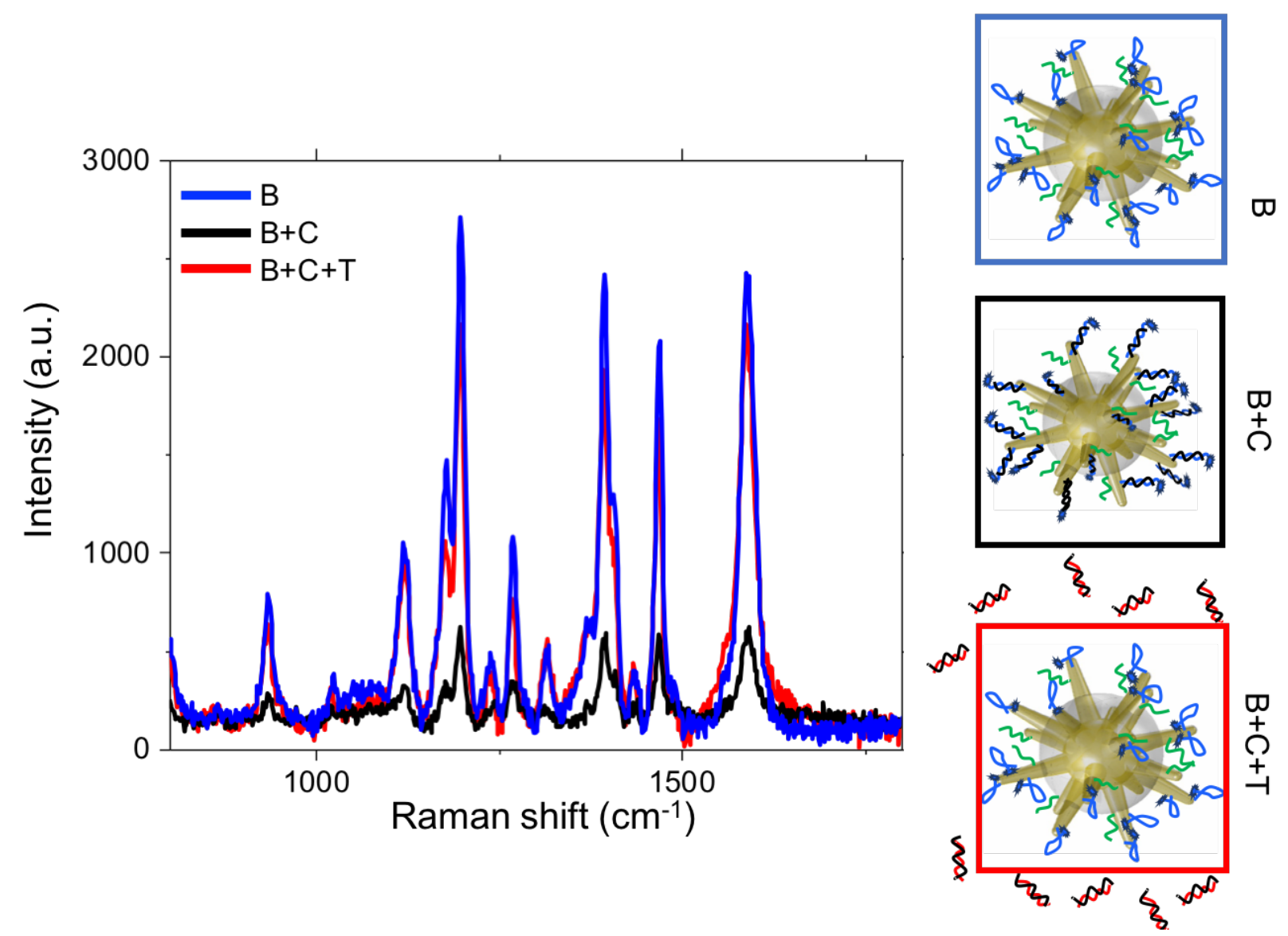

Figure S4. Representation of the stability of SANSPs that were prepared at $37^{\circ} \mathrm{C}$ and tested against the target RNA at $37^{\circ} \mathrm{C}$. "B" indicates the nanostars conjugated to the beacon in its hairpin conformation. " $\mathrm{B}+\mathrm{C}$ " represents the nanostars conjugated to the beacon hybridized to its complementary strand. "B+C+T" represents the configuration achieved after target RNA introduction, which leads to dehybridization of the complementary strand from the nanostar, followed by its hybridization to the target RNA and folding of the beacon back into hairpin conformation. 


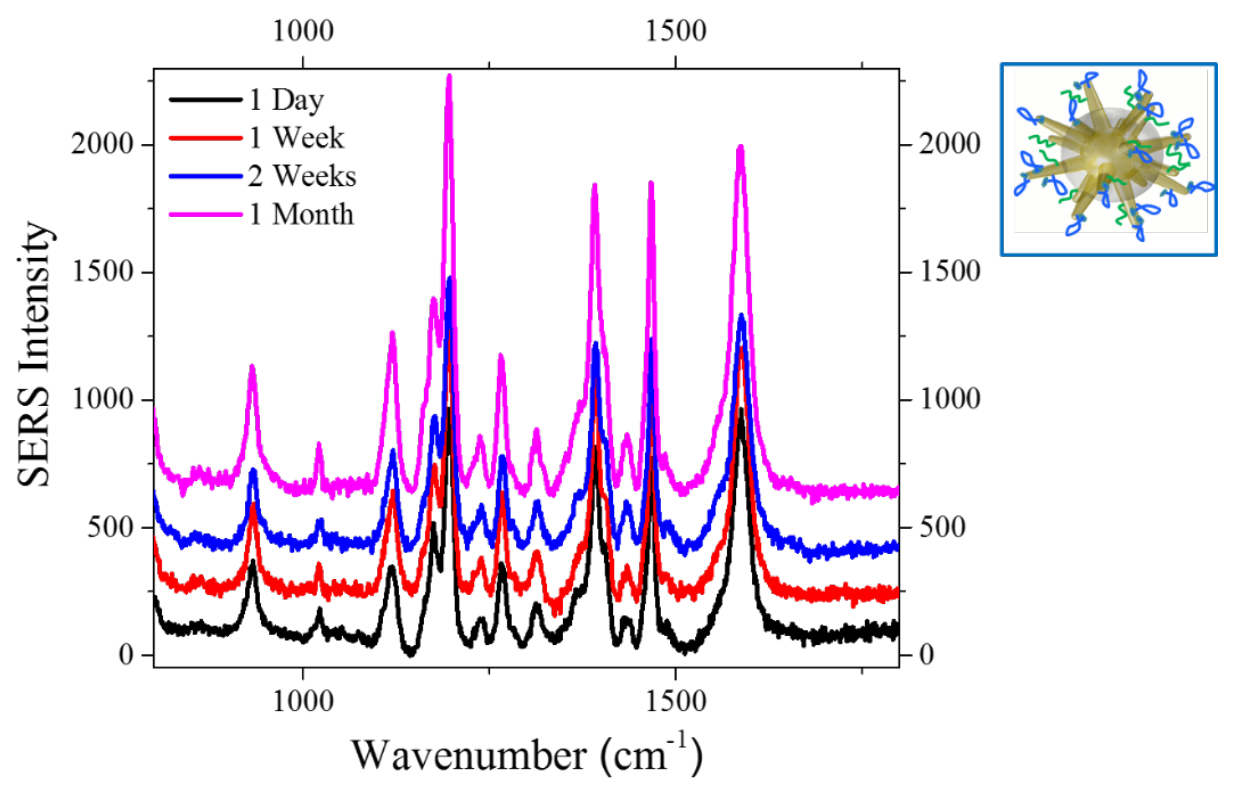

Figure S5. Stability of SANSPs over time for the configuration shown in the boxed illustration.

a)

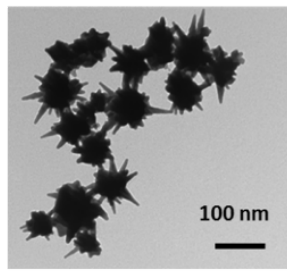

d)

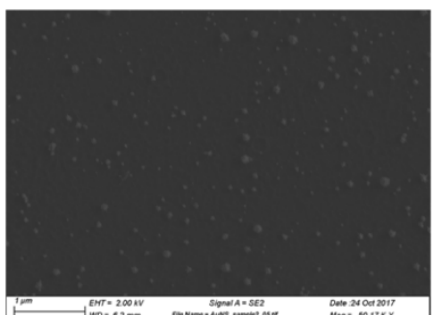

e)

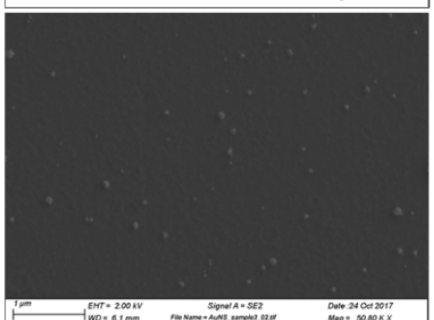

b)

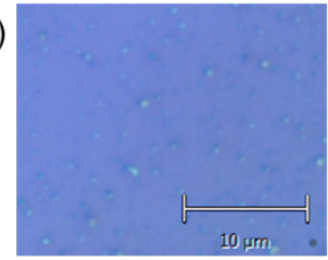

Image-J

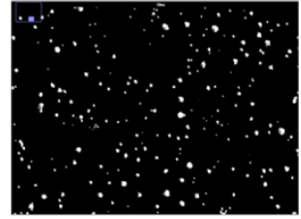

Image-J

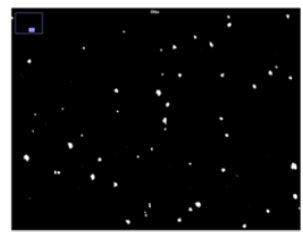

c)

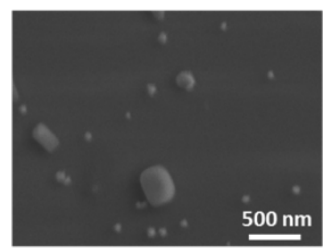

Size distribution

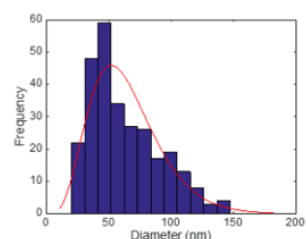

Size distribution

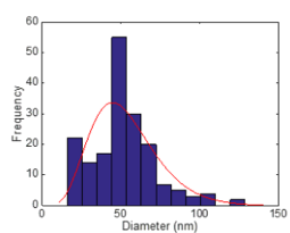

Figure S6. a) TEM micrograph of the synthesized surfactant-free gold nanostars; b) Bright field image of the SERS substrate with a sub-monolayer of gold nanostars immobilized on Si wafer substrate; c) SEM image of single gold nanostars well separated from each other on Si wafer substrate; d, e) SEM images of SERS substrates prepared with diluted concentrations of gold nanostars immobilized on glass slide to achieve sub-monolayer coverage; Image-J analysis of the nanostar sizes. 
a)

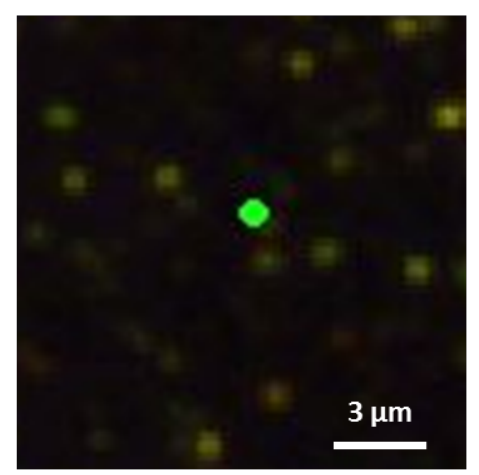

c)

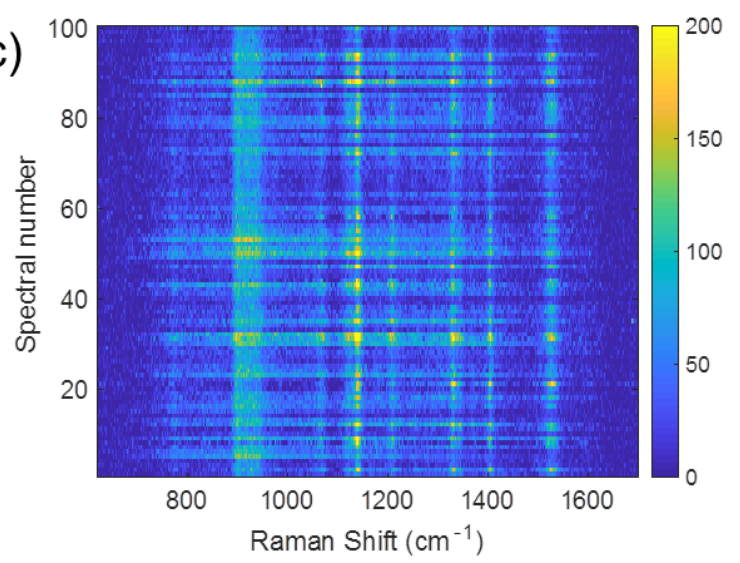

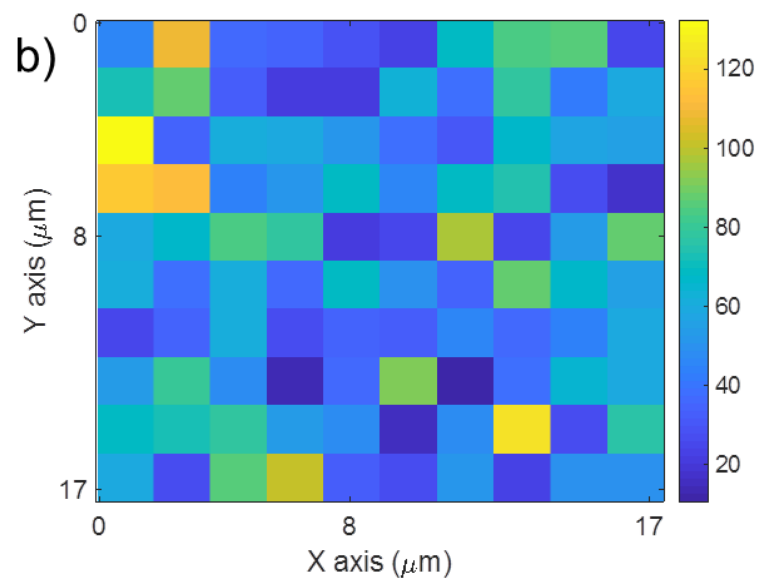

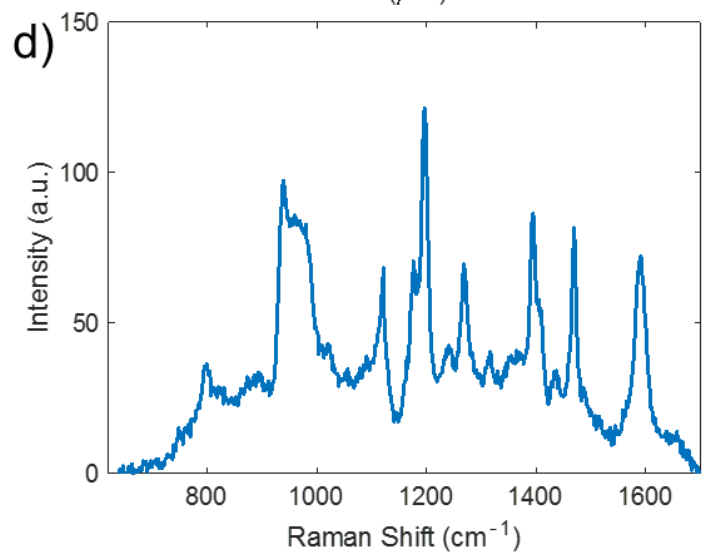

Figure S7. a) Dark-field image of the sub-monolayer gold nanostars immobilized on glass slide. Bright green spot is the cross-hair position in the DF view; b) Raman map based on the peak intensity of a characteristic Cy3 band at $1590 \mathrm{~cm}^{-1}$; c) stacked SERS spectra collected from each individual pixels in b); d) averaged SERS spectra from the mapping collection ( $n=100)$. 
$\mathrm{P1}$
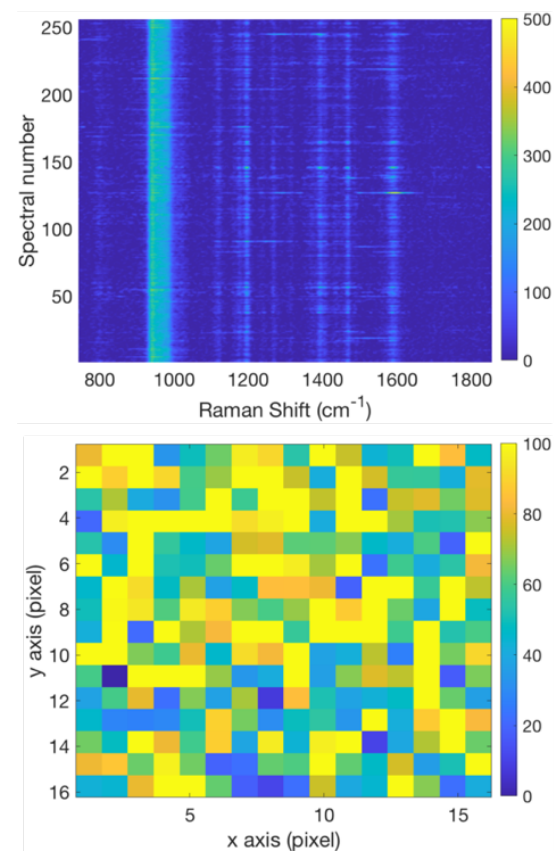

P2
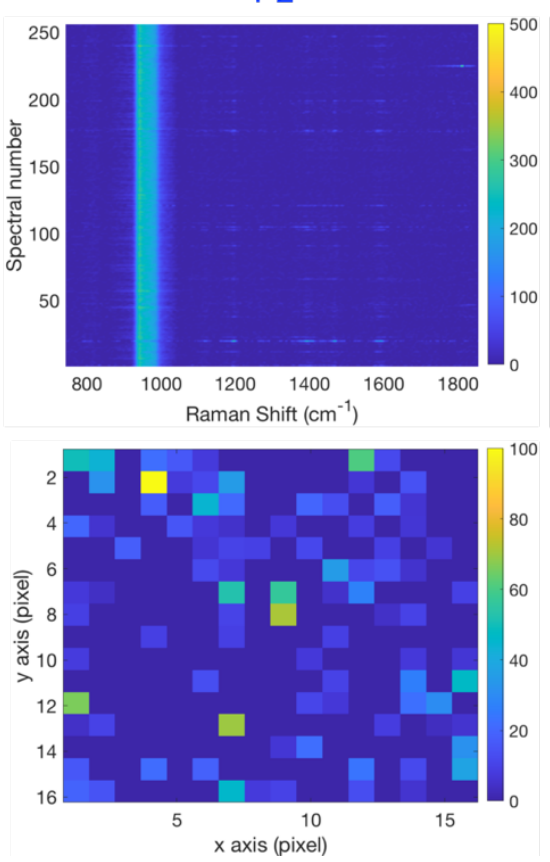

P3
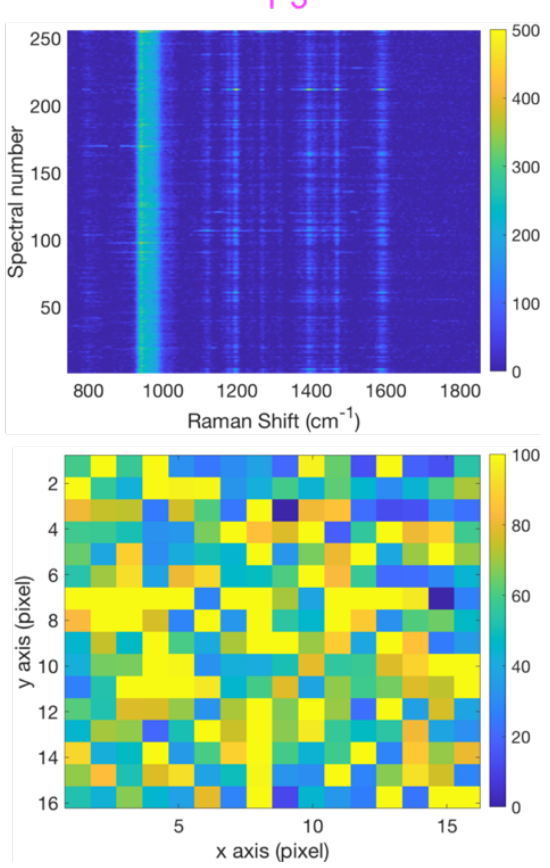

Figure S8. Upper panel: false-color heatmaps generated from Raman mapping of sub-monolayer nanoparticle substrates after each treatment as depicted in Figure 2. Lower panel: corresponding reconstructed Raman maps based on the peak intensities of a characteristic Cy3 band at 1590 $\mathrm{cm}^{-1}$ in the SERS spectra collected from each individual pixels $(n=256)$. 

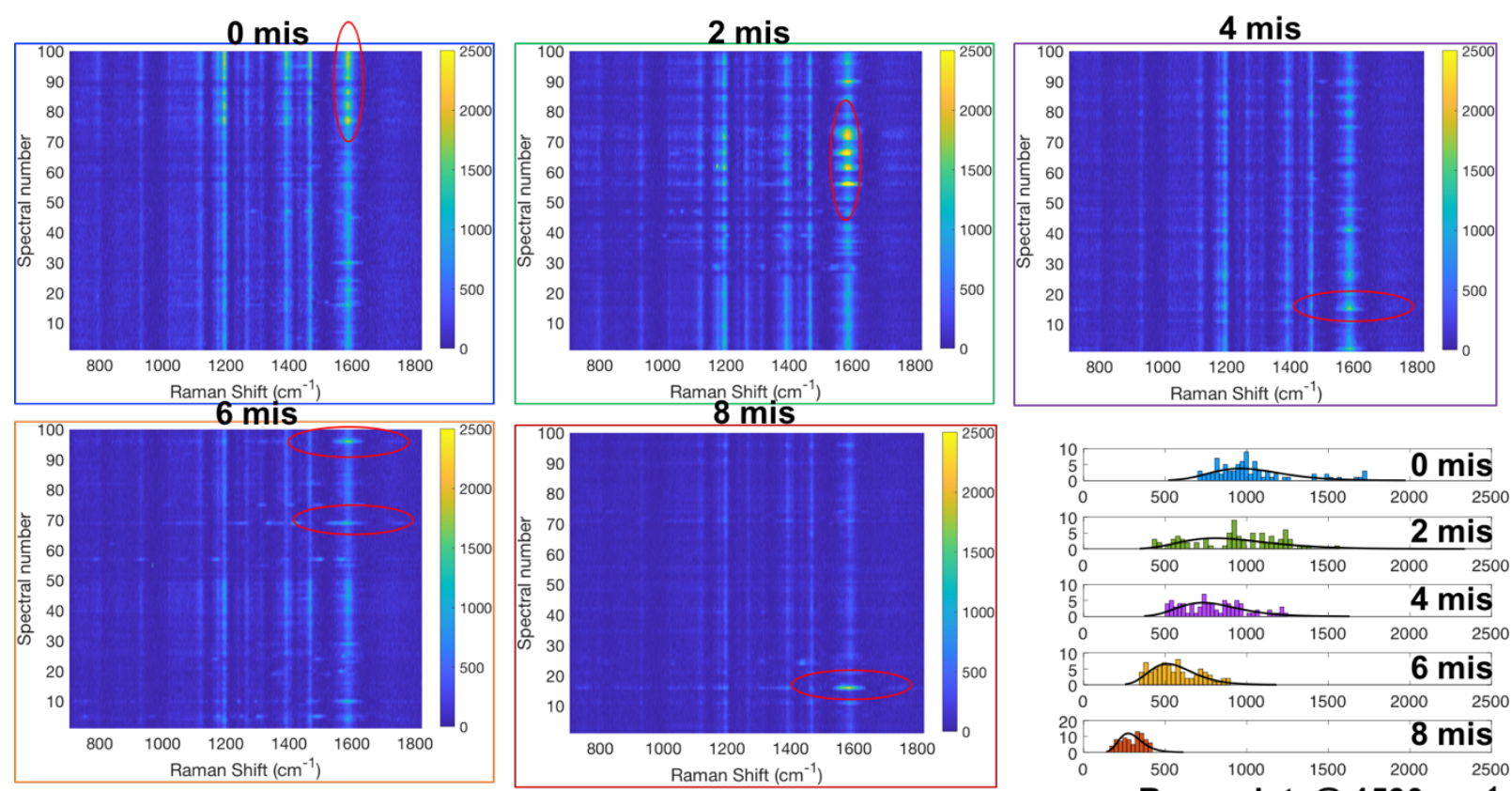

Raman int. @ 1590 cm$^{-1}$

Figure S9. False-color heatmaps constructed with SERS spectra measured after hybridization of SANSPs with RNA targets with different numbers of mutations $(0,2,4,6,8$ mutations in targets, respectively). Corresponding histogram distributions of the peak intensities of a characteristic Cy3 band at $1590 \mathrm{~cm}^{-1}$ in the SERS spectra fitted with a normal distribution function (signal outliers were excluded in the histogram plot and the boxplot in Figure 3b; signal outliers were marked by red ovals).

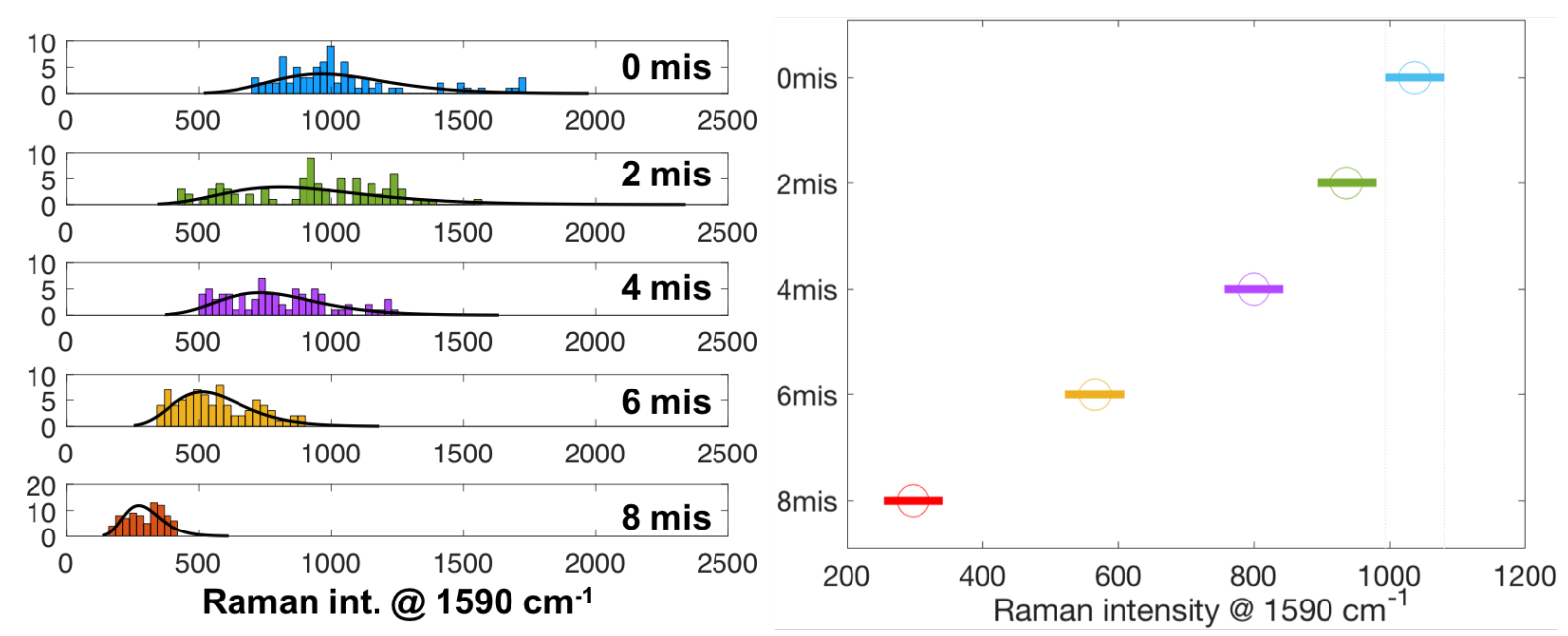

Figure S10. Histogram distributions of the peak intensities of a characteristic Cy3 band at 1590 $\mathrm{cm}^{-1}$ in the SERS spectra fitted with a normal distribution function (signal outliers were excluded in this histogram plot and the boxplot in Figure 3b); Corresponding group means (circle) and 95\% confidence intervals (vertical lines) of the mean from the One-Way ANOVA analysis. 


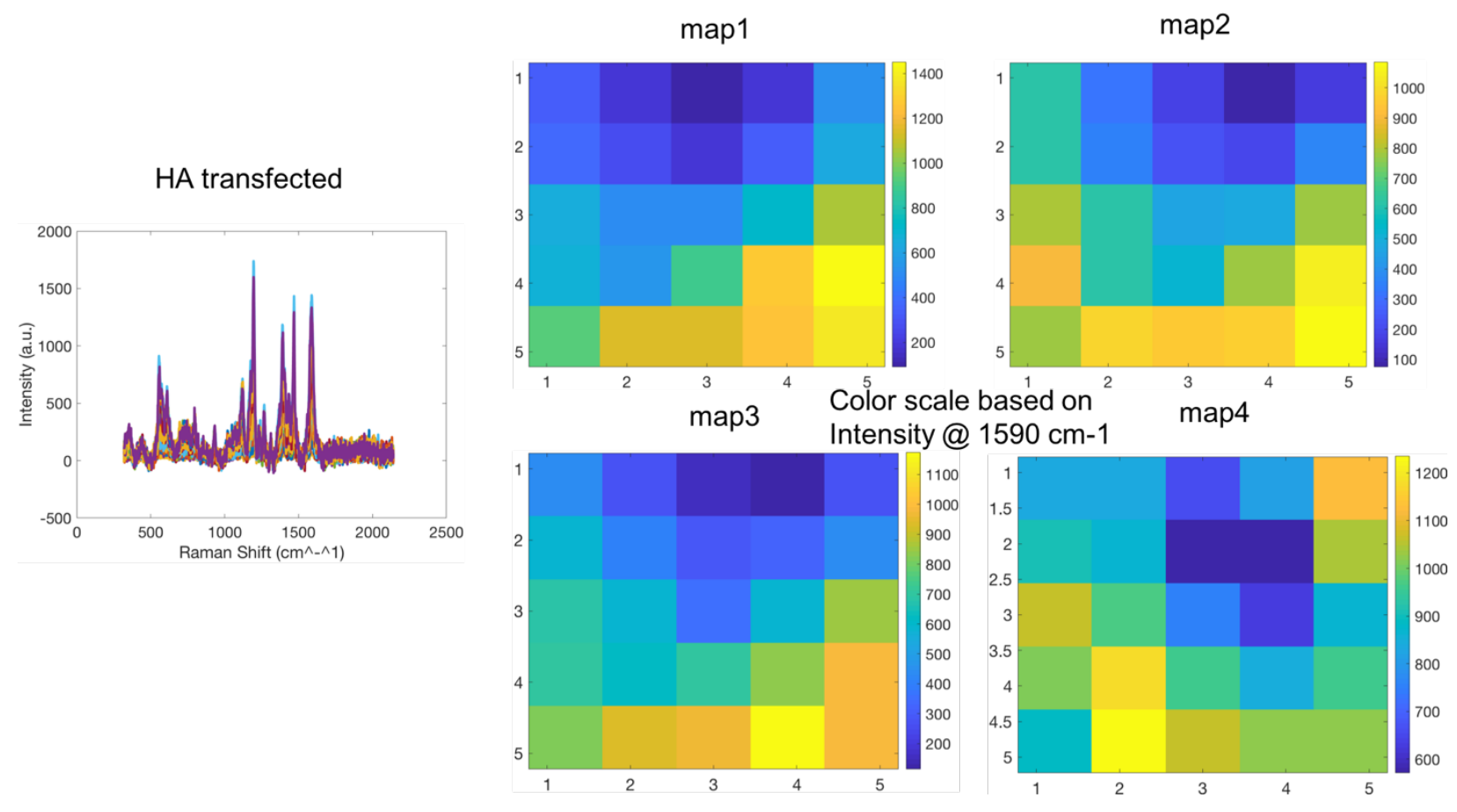

Figure S11. Raman mapping (x4 maps, intensity at $1590 \mathrm{~cm}^{-1}$ ) of each individual intact HeLa cells transfected by HA plasmids. Raman spectra were compiled in the figure on the left. 

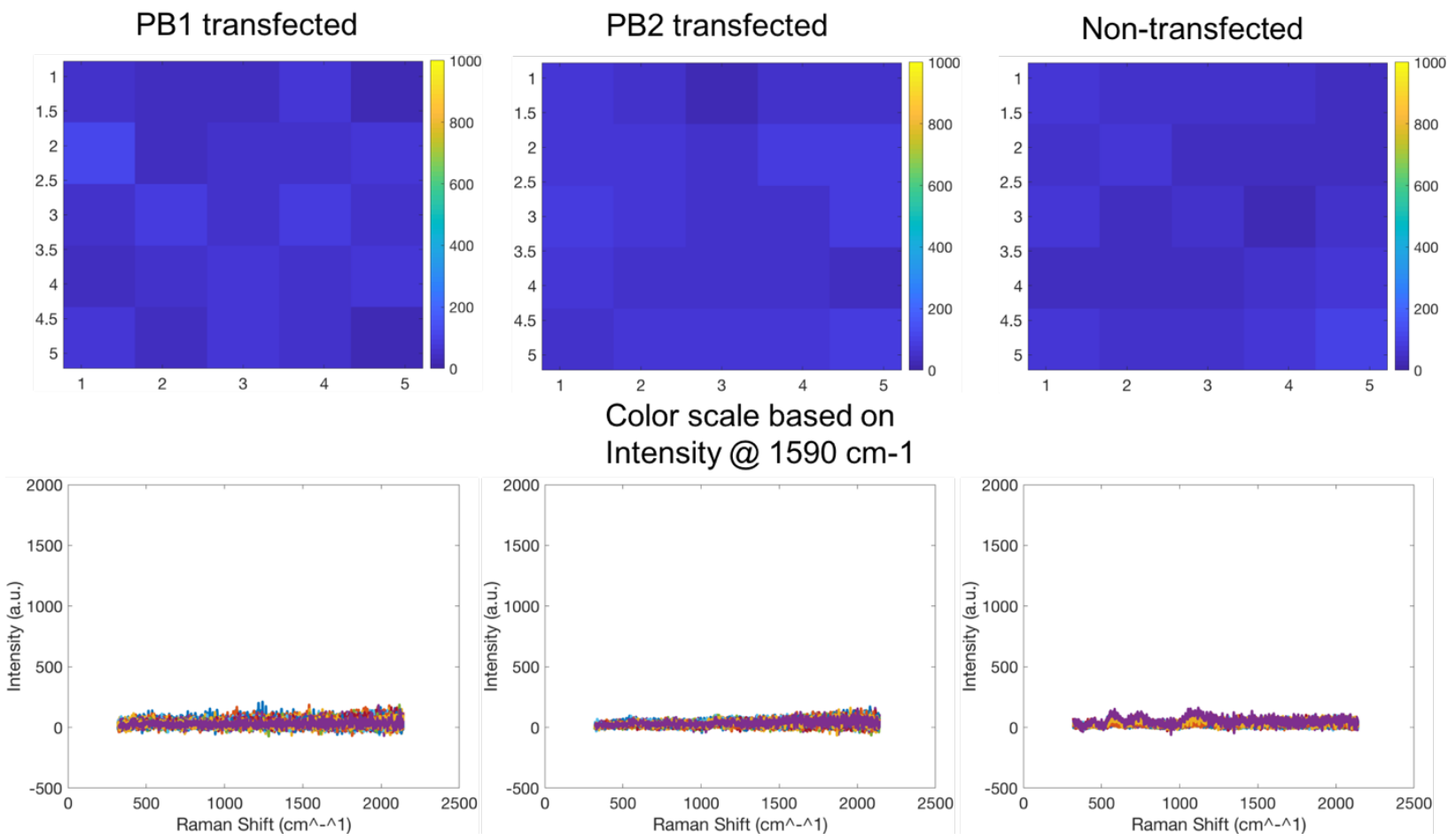

Figure S12. Representative Raman maps (intensity at $1590 \mathrm{~cm}^{-1}$ ) collected from intact HeLa cells transfected by either PB1, PB2 or no plasmids. Raman spectra were compiled in the figure in the bottom row. 


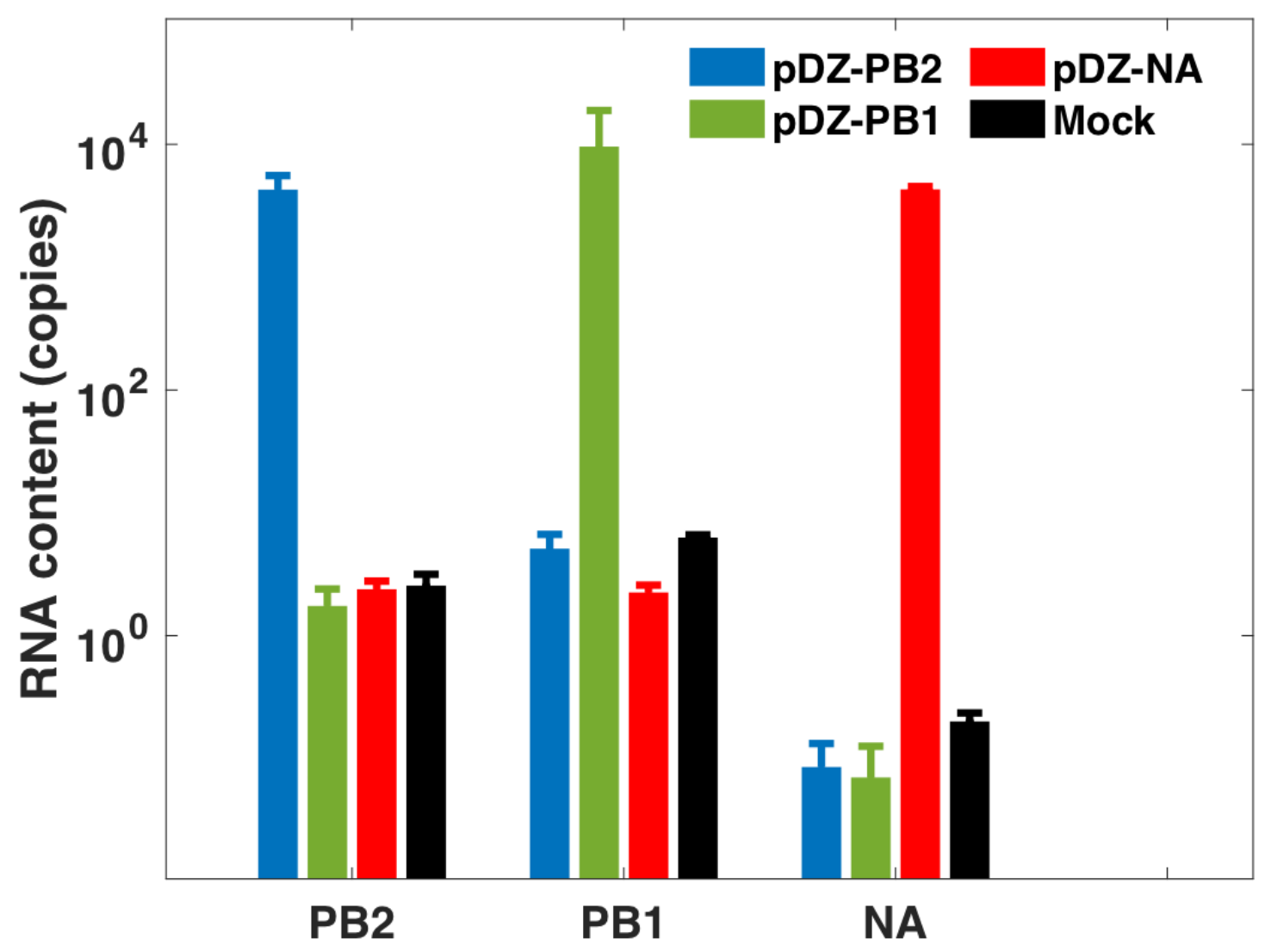

Figure S13. Bar graph of the intracellular RNA expression quantified by gene-specific RT-qPCR after Hela cells were transfected with pDZ-PB2, pDZ-PB1, pDZ-NA or lack of plasmids for mock. Hela cells were collected 24 hours post-transfection and then cellular RNA were extracted and analyzed. With gene specific primer pairs for the quantification of plasmid transfected Hela cells revealed HA had $4.30 \times 10^{3}$ copies in the HA-transfected Hela cells, which was comparable to PB2- and PB1-transfected Hela cells with $4.28 \times 10^{3}$ and $9.58 \times 10^{3}$ copies of PB2 and PB1 RNA segments, respectively. Additionally, the mock group did not show any significant amplification of each of the 3 gene segments, with copy numbers ranging from 0-6. 
Table S1 The sequences synthesized and ordered from IDT to develop and test SANSPs. The sequences originate from 5'-TCA TTT TTG TTG CTT TTG TTT -3' located in the conserved region of IAV segment 4 . Here, targets were all RNA oligonucleotides, therefore, $T$ in these targets should be replaced with $U$.

\begin{tabular}{|c|c|}
\hline Sequence Name & Sequence \\
\hline $\begin{array}{l}\text { 2-Mismatch } \\
\text { Beacon }\end{array}$ & 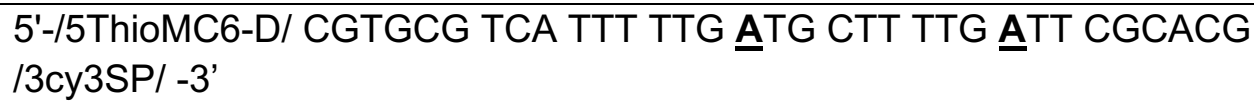 \\
\hline Complementary & 5'- AAA CAA AAG CAA CAA AAA TGA -3' \\
\hline Random & 5'- TTT TAT CCT TCA TCT CTT GTA -3' \\
\hline $\begin{array}{l}\text { 0-Mismatch } \\
\text { Target }\end{array}$ & 5'-TCA TTT TTG TTG CTT TTG TTT-3' \\
\hline $\begin{array}{l}\text { 2-Mismatch } \\
\text { Target }\end{array}$ & 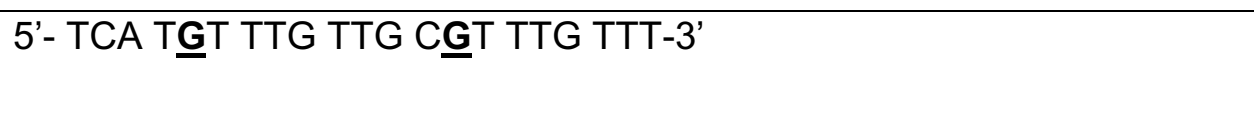 \\
\hline $\begin{array}{l}\text { 4-Mismatch } \\
\text { Target }\end{array}$ & 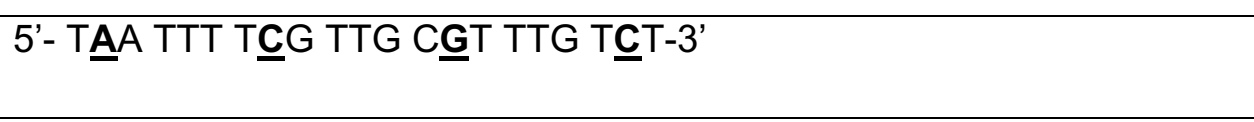 \\
\hline $\begin{array}{l}\text { 6-Mismatch } \\
\text { Target }\end{array}$ & 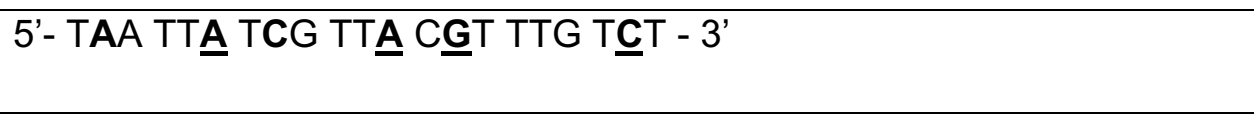 \\
\hline $\begin{array}{l}\text { 8-Mismatch } \\
\text { Target }\end{array}$ & 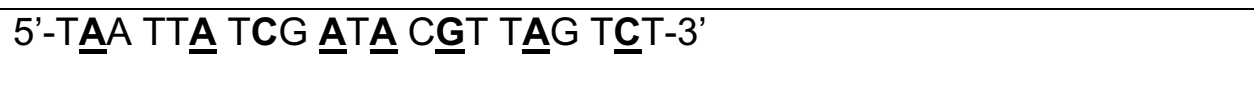 \\
\hline
\end{tabular}


Table S2 The thermodynamic properties of the designed beacon structures; beacon hybridization with the complementary, as well as target-complementary hybridization.

\begin{tabular}{|c|c|c|c|c|c|c|}
\hline Beacon name & Sequence & \multicolumn{2}{|c|}{$\Delta G\left(\right.$ kcal.mole $\left.{ }^{-1}\right)$} & $\mathrm{T}_{\mathrm{m}}\left({ }^{\circ} \mathrm{C}\right)$ & $\Delta \mathrm{H}\left(\right.$ kcal.mole $\left.{ }^{-1}\right)$ & $\Delta \mathrm{S}\left(\mathrm{cal}^{\mathrm{K}} \mathrm{K}^{-1} \mathrm{~mole}^{-1}\right)$ \\
\hline $\begin{array}{l}\text { 2-mis beacon } \\
\text { DNA }\end{array}$ & $\begin{array}{l}\text { 5'-/5ThioMC6-D/CGTGCG } \\
\text { TCA TTT TTG } \underline{\mathbf{A} T G} \text { CTT } \\
\text { TTG } \underline{\mathbf{A} T T} \text { CGCACG } \\
\text { /3cy3P/ } /-3 \text { ' }\end{array}$ & \multicolumn{2}{|c|}{-5.42} & 58.2 & -54 & -165.95 \\
\hline Beacon name & \multicolumn{2}{|c|}{ Sequence } & \multicolumn{3}{|c|}{ Beacon-Complementary hybridization } & $\Delta \mathrm{G}\left(\right.$ kcal.mole $\left.{ }^{-1}\right)$ \\
\hline 2-mis beacon DNA & \multicolumn{2}{|c|}{$\begin{array}{l}\text { 5'-/5ThioMC6-D/CGTGCG TCA } \\
\text { TTT TTG } \underline{A} \text { TG CTT TTG } \underline{\text { ATT }} \\
\text { CGCACG /3ey3P/-3' }\end{array}$} & \multicolumn{3}{|c|}{ 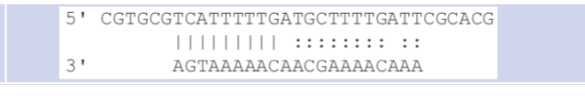 } & -14.73 \\
\hline Target name & Sequence & \multicolumn{4}{|c|}{ Target-Complementary hybridization } & $\Delta \mathrm{G}\left(\mathrm{kcal}^{\mathrm{mole}} \mathrm{m}^{-1}\right)$ \\
\hline 0-mis target & 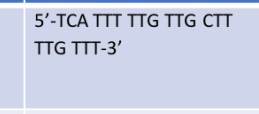 & \multicolumn{4}{|c|}{$\begin{array}{l}\text { 5' AAACAAAAGCAACAAAAATGA } \\
\text { 1 } 11|||||||||||||||||||||| \\
\text { 3' TTTGTTTCGTTGTTTTACT }\end{array}$} & -37.73 \\
\hline 2-mis target & 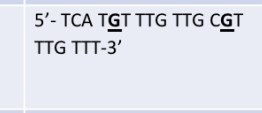 & \multicolumn{4}{|c|}{$\begin{array}{l}\text { 51 AAACAAAAGCAACAAAAATGA } \\
\quad:::::: \quad|||||| \mid:::: \\
31 \text { TITGTTTGCGTTGTTTGTACT }\end{array}$} & -14.22 \\
\hline 4-mis target & 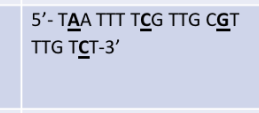 & \multicolumn{4}{|c|}{$\begin{array}{l}\text { 5. AAACAAAAGCAACAAAAATGA } \\
\quad:::::: 1111 \text { : : : : : : } \\
\text { 3' TCTGTTTGCGTTGCTTTTAAT }\end{array}$} & -8.38 \\
\hline 6-mis target & 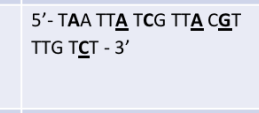 & \multicolumn{4}{|c|}{$\begin{array}{l}\text { 5' AAACAAAAGCAACAAAAATGA } \\
: \quad 11111::::::::: \\
\text { 31 }: \text { TCTGTTTGCATIGCTATTAAT }\end{array}$} & -7.18 \\
\hline 8-mis target & 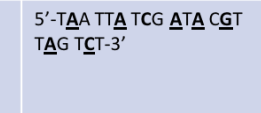 & \multicolumn{4}{|c|}{$\begin{array}{l}\text { 5' AAACAAAAGCAACAAAAATGA } \\
::::::::::=111: \\
\text { 3' TCTGATTGCATAGCTATTAAT }\end{array}$} & -3.42 \\
\hline
\end{tabular}

Table S3 The statistics of multiple comparisons for One-Way ANOVA.

\begin{tabular}{|c|c|c|c|c|c|}
\hline \multicolumn{2}{|c|}{ Paired-groups } & $\begin{array}{c}\text { Lower confidence } \\
\text { interval }\end{array}$ & Estimate & $\begin{array}{l}\text { Upper confidence } \\
\text { interval }\end{array}$ & $\begin{array}{l}p \text {-value for the } \\
\text { hypothesis test }\end{array}$ \\
\hline Omis & $2 \mathrm{mis}$ & 13.3967557 & 100.173529 & 186.950302 & 0.01417254 \\
\hline Omis & $4 \mathrm{mis}$ & 150.102671 & 236.879444 & 323.656217 & 9.92E-09 \\
\hline Omis & $6 \mathrm{mis}$ & 384.932035 & 471.708808 & 558.485581 & 9.92E-09 \\
\hline Omis & $8 \mathrm{mis}$ & 652.129277 & 738.90605 & 825.682823 & 9.92E-09 \\
\hline $2 \mathrm{mis}$ & $4 \mathrm{mis}$ & 49.9291424 & 136.705915 & 223.482689 & 0.00016813 \\
\hline $2 \mathrm{mis}$ & $6 \mathrm{mis}$ & 284.758506 & 371.535279 & 458.312052 & 9.92E-09 \\
\hline $2 \mathrm{mis}$ & $8 \mathrm{mis}$ & 551.955748 & 638.732521 & 725.509294 & 9.92E-09 \\
\hline $4 \mathrm{mis}$ & $6 \mathrm{mis}$ & 148.052591 & 234.829364 & 321.606137 & 9.92E-09 \\
\hline $4 \mathrm{mis}$ & $8 \mathrm{mis}$ & 415.249832 & 502.026606 & 588.803379 & 9.92E-09 \\
\hline $6 \mathrm{mis}$ & $8 \mathrm{mis}$ & 180.420469 & 267.197242 & 353.974015 & 9.92E-09 \\
\hline
\end{tabular}




\section{References.}

1. Yuan, H.; Khoury, C. G.; Hwang, H.; Wilson, C. M.; Grant, G. A.; Vo-Dinh, T., Gold Nanostars: Surfactant-Free Synthesis, 3d Modelling, and Two-Photon Photoluminescence Imaging. Nanotechnology 2012, 23, 075102.

2. Turkevich, J.; Stevenson, P. C.; Hillier, J., A Study of the Nucleation and Growth Processes in the Synthesis of Colloidal Gold. Faraday Discuss. 1951, 11, 55-75.

3. Atta, S.; Tsoulos, T. V.; Fabris, L., Shaping Gold Nanostar Electric Fields for SurfaceEnhanced Raman Spectroscopy Enhancement Via Silica Coating and Selective Etching. The J. Phys. Chem. C 2016, 120, 20749-20758.

4. Breen, M.; Nogales, A.; Baker, S. F.; Martinez-Sobrido, L., Replication-Competent Influenza a Viruses Expressing Reporter Genes. Viruses 2016, 8.

5. $\quad$ Cheng, Y.; Stakenborg, T.; Van Dorpe, P.; Lagae, L.; Wang, M.; Chen, H.; Borghs, G., Fluorescence near Gold Nanoparticles for DNA Sensing. Anal. Chem. 2011, 83, 1307-1314.

6. Jimenez de Aberasturi, D.; Serrano-Montes, A. B.; Langer, J.; Henriksen-Lacey, M.;

Parak, W. J.; Liz-Marzán, L. M., Surface Enhanced Raman Scattering Encoded Gold Nanostars for Multiplexed Cell Discrimination. Chem. Mater. 2016, 28, 6779-6790.

7. Faulds, K.; Smith, W. E.; Graham, D., Evaluation of Surface-Enhanced Resonance Raman Scattering for Quantitative DNA Analysis. Anal. Chem. 2004, 76, 412-7.

8. $\quad$ Nath, N.; Chilkoti, A., A Colorimetric Gold Nanoparticle Sensor to Interrogate Biomolecular Interactions in Real Time on a Surface. Anal.I Chem. 2002, 74, 504-509.

9. Atta, S.; Rangan, S.; Fabris, L., Highly Tunable Growth and Etching of Silica Shells on Surfactant - Free Gold Nanostars. ChemNanoMat 2019, DOI: DOI: 10.1002/cnma.201900459 